\title{
Ethnography and international relations: situating recent trends, debates and limitations from an interdisciplinary perspective
}

\author{
Jean Michel Montsion
}

Correspondence:

jmmontsion@glendon.yorku.ca Department of Multidisciplinary Studies, Glendon College, York University, 2275 Bayview Avenue, Toronto, Ontario M4N 3M6, Canada

\begin{abstract}
As a relatively recent academic discipline, international relations engage with ethnography in specific ways, especially since its ethnographic turn starting in the mid-1990s. Conceived as a methodology that may open up the field to new perspectives on studying world politics, ethnography is deployed by critical IR scholars in order to ground everyday life as a credible source of knowledge about the international realm. Despite disciplinary and logistical challenges, recent attempts to integrate ethnography into IR can be found in practice-focused research, autoethnography and multi-sited studies. Following an examination of how ethnography has been interpreted and utilised in these cases, the paper will highlight commonalities with debates in other fields, especially social anthropology, to offer new avenues for a richer engagement with ethnography in IR.
\end{abstract}

Keywords: Disciplinarity, Ethnography, International relations, Methodology

\section{Background}

The discipline of international relations (IR) has a relatively short academic history. Emerging after the First World War as a separate field of study within political science, IR went through five "great debates" which helped define its distinct objects of study, its main concerns at specific moments in time, its enduring conceptual tools and the ways in which it helps explain contemporary trends in world politics. For instance, the first debate is said to have juxtaposed realists and idealists during the interwar period in a debate over whether war between nation-states is inevitable, or whether cooperation can result in lasting peace (Ashworth 2002; Schmidt 1998; Smith 2000). By positioning themselves within these five debates, mainstream approaches to IR emerge as problem-solving perspectives, with the aim of providing foreign policy advice to state officials and utilising quantitative methodologies, based on rationalist and positivist precepts. In order to study the unique structures and processes that emerge from state interactions, scientific approaches are seen here as helpful in explaining the big picture, predicting what could happen and offering concrete advice to practitioners.

In contrast, critical scholarship in IR is inspired by post-positivist and reflexive research approaches. Rather than trying to explain world politics in reductive ways, critical approaches attempt to understand the complexities and nuances of IR, including

(c) The Author(s). 2018 Open Access This article is distributed under the terms of the Creative Commons Attribution 4.0 International License (http://creativecommons.org/licenses/by/4.0/), which permits unrestricted use, distribution, and reproduction in any medium provided you give appropriate credit to the original author(s) and the source, provide a link to the Creative Commons license, and indicate if changes were made. 
by focusing on non-state voices as key actors, by opting for non-scientific methodologies, and by deconstructing how a sovereign state is conceived and expected to act (Cox and Sinclair 1996; Hoffman 1993; Hollis and Smith 1990). Interestingly, it is within this latter type of IR scholarship that ethnography is located. Whereas other social sciences like anthropology and sociology have a longer and more plural engagement with this methodology, including its scientific conceptualisation and deployment (see Hua 2008, Small 2009), the ethnographic turn in IR is found in post-positivist, reflexive and subjectivist scholarship. Specifically, and in contrast to its use in social anthropology, where it is seen as a complex and diverse body of literature encompassing approaches from varied positivist and post-positivist commitments alike, ethnography is deployed in IR as a methodological counter-weight to mainstream quantitative methodological approaches in the field (Aradau and Huysmans 2014:598-600).

The overall ability to problematise state-centrism by focusing on every day and bottom-up ways of conducting research, especially in the case of social facts with a transnational or international component, is seen as appealing to critical IR researchers. Their growing interest since the mid-1990s fits well with Comaroff and Comaroff $(1992,2003)$ observation that while ethnography became less popular within anthropology starting at the end of the 1980s, there has been increased interest by researchers in other social sciences, because it is conceived as a way to reduce state-centrism in making linkages between local and global realities, at a time when processes associated with globalisation have become increasingly important factors (Vrasti 2008:280). After the dominance of the linguistic turn in critical IR scholarship, in which the main focus was on discourses, the ethnographic turn was seen as a way to move beyond such analysis and to focus on everyday life as a prime site of international inquiry (Lie 2013:202). By providing "an empirically nuanced account derived from 'being there' on a daily basis", IR's ethnographic turn is associated with analyses that either try to "study up" professional circles that heavily influence the practice of the international, or to examine the experiences of marginalised populations affected by cross-border and transnational processes (Johnson 2014b; Kuus 2013). The appeal of ethnography is that it complements discursive analyses, moves beyond the mainstream perspectives of conventional actors such as states and international organisations, and sheds new light on under-explored knowledge, linkages and understandings of world politics.

Ethnography is not a conventional methodology in IR, and its popularity is quite recent. As such, its deployment has been limited to specific epistemological commitments, which has influenced the body of literature from other disciplines that has been selected to help its users comprehend and deploy it. In light of the work by Wanda Vrasti (2008), Aradau and Huysmans (2014), it will be argued here that it is not productive to limit IR's engagement with this methodology to its ethnographic turn, as this move limits the potential and complexities of engaging with what ethnography has to offer, especially when utilised in other disciplines from various epistemological and methodological perspectives. As a scholar well-versed in critical IR scholarship, and not in social anthropology, I unpack how ethnography is utilised and debated in different IR approaches in recent years to allow for a deeper understanding of its general utility while providing parallels to discussions that have occurred in other disciplines, including social anthropology. IR's disciplinary instincts to avoid sustained conversations with other disciplines that are well versed in ethnography is a key limitation of the methodology's resonance in the field. 


\section{Methods}

\section{Notes on the methodological analysis ahead}

Coming out of an academic workshop on new and recent ways to engage with ethnography in globalised times, the intent here is twofold: to provide an interdisciplinary perspective on how IR has engaged with ethnography in order to inform scholars and practitioners trained in other disciplines; and to open up IR scholarship to interdisciplinary avenues in order to deepen its engagement with ethnography. Methodologically, this reflexive literature review offers new insights through the juxtaposition of disciplinary knowledges and debates. Similar contributions to IR have been recognised in the field as helping to bring new conceptual tools, perspectives and insights into IR, a field often characterised by its fortress mentality and disciplinary blinders (see Eriksen and Neumann 1993; Ree 2014; Waever 1998). Therefore, the aim is neither to evaluate where proper forms of ethnography are deployed in IR nor is it to evaluate the quality and potential use of ethnographic approaches from other academic fields. It is, rather, to document how ethnography is used in IR, and where some bridges to other disciplinary debates or authors in other disciplines can be made.

After situating how ethnography is utilised in IR and the specific disciplinary challenges that arise from this usage, three vignettes of recent accounts of how ethnography is interpreted and deployed in the field will be explored, namely, practice-focused research, autoethnography and multi-sited studies. While this is by no means an exhaustive list, these types of vignettes are useful in examining the ways in which IR engages with ethnography and in highlighting some commonalities with methodological debates in other academic fields.

\section{Theoretical lens}

\section{Challenges in conceptualising and using ethnography in IR}

Iver B. Neumann (2010), a leading IR scholar who was also trained in anthropology, once indicated that each discipline has a very different research intent: "A different exercise, which call[s] for a different writing style" (Neumann 2010:1054). Whereas IR generally opts for a top-down or deductive approach, social anthropology, through ethnography, turns to a bottom-up perspective on investigating the world. In this section, I start with the abstractions that define IR as an academic field to show how ethnography has been integrated, especially in IR's critical scholarship. I suggest that the disciplinary practices of the field are responsible for ethnography's limited presence, which include the lack of training offered to the next generation of scholars and the various challenges related to fieldwork logistics and deploying a bottom-up methodological approach in a deduction-prone academic discipline. I also reflect on some lessons from social anthropology for IR scholars for avoiding pitfalls in designing and conducting ethnographies of the international.

Critical IR scholars have long indicated that their academic field is built on conceptual abstractions that are meant to separate the study of the international realm from the reality of living within a political community. Key to this distinction is a focus on the context of anarchy in which sovereign states interact. Richard Ashley (1988:227) re-states this dominant position in the field as follows:

They start from the premise that the world is to be understood not only in terms of the absence of a central agency of rule but also in terms of the presence of a 
multiplicity of states, each understood as a sovereign identity presiding over its respective national society and making decisions in the interests thereof.

For Ashley, pointing out the anarchy of the international realm is meant to reify state sovereignty as more important than any other principle or reality within IR. This perspective is consistent with Rob Walker's (2006) emphasis on the various binary oppositions and conceptual categories on which IR inquiries are based: inside/outside, sovereignty/anarchy, friends/enemies, morality/instrumentality, and rules-based/power politics. The academic discipline of IR has maintained its distinctiveness not only through these conceptual categories, but also by building a field that has a separate object of study, separate from what is examined within a state.

This intellectual exercise and related abstractions are presented as value-free and non-normative assumptions about world politics; hence, making anarchy and state sovereignty facts from which any IR inquiry starts. However, Steve Smith (2004) argues that these representations contribute to an unstable and violent world order, especially when translated into methodological preferences for rational choice and game theory. According to these theories and related deductive methodologies, states, as self-interested sovereign entities, will necessarily clash with other states to maximise their claim to power and resources. These methodologies are therefore of limited usefulness when we problematise the assumption that states are egotistical unitary actors engrained in mainstream theoretical approaches.

Despite their limitations, such assumptions are not easily questioned because they are supported by a logic of disciplinarity and the academic fragmentation of knowledge. IR scholars study what happens between states, so foundational concepts such as state sovereignty are more than abstractions. They are intertwined in the broader aim of IR in the pursuit of knowledge and supported by privileged state-centrist and deductive methodologies that do not question these premises (Beier 2005:64-65; Schmidt 1998). IR scholarship hermetically combines questions of ontology, epistemology and methodology, and is often characterised by having mainstream approaches that are hard to engage with from a different perspective (Zalewski 2006:46-51). IR's disciplinary logic also tends to translate into a reluctance to experiment with other methodologies than the ones privileged by mainstream scholarship, including ethnography, which is often met with the mainstream's "defensive reaction to uncertainty" (Beier 2005:70).

Since its ethnographic turn in the 1990s, some IR scholars have tried to engage with this methodology as a way to "[go] out and [get] close to the activities and experiences of other people, observing and interacting with informants preferably over a longer period of time", with the aim of "seeing the informant's world from his [sic.] own perspective, and the dilemma of reconciling participation and observation" (Lie 2013:204). One key intent of critical scholarship has been to bring "ethnographic sensibility [in] to the study", which sets specific parameters for integrating ethnography into a very abstract field (Kuus 2013:118). Ethnography in IR is conducted in ways that usually reflect:

less emphasis on bounded communities in bounded places and more on tracing the connective flows and networks of ideas and people. Although they use the 
idiom of ethnographic fieldwork and writing, the actual empirical analysis is built on a mix of interviews, documentary analyses, and some ethnographic observations (Kuus 2013:117).

As such, IR's take on ethnography has been adapted from some contemporary anthropological scholarship focused on connections and associations among different territorial sites. IR's engagement to some extent obscures classical ethnographies emphasising the importance of cross-territorial comparisons (see Mauss, 2002) or different geographically specific moments and temporal connections (see Geertz 1980; Mandelbaum 1973). Its engagement here overemphasises the commitment by some within anthropology to be less focused on its traditional use to understand a locally experienced, multi-location, inter-cultural and globalised world (Abélès 2011; Falzon 2009; Marcus 1986; Lie 2013).

It is important to note that, prior to the so-called ethnographic turn, ethnography was used somewhat in IR's feminist scholarship, which is positioned within the post-positivist and reflexive tradition of the field, especially since the 1980s. As Ann Tickner (2006:2021) indicates, "there is no unique feminist research method", as the goal of knowledge contribution here is an "ongoing process... emerging through conversation with texts, research subjects, or data". In a discipline that mostly relies on the "objectivity of the natural sciences", feminist IR scholarship grounds its credibility in methodologies that are seen as less-than-scientific and that embrace subjectivity (Zalewski 2006:46).

Building on George E. Marcus' multi-sited ethnography, feminist IR grounds its inquiry in scholarship that has experimented with a combination of qualitative methods and the sensibilities of ethnography. Speaking about her own method of investigating American national security discourses, Carol Cohn (2006:107) notes:

My method derives its strength from the juxtaposition and layering of what I found in different sites, in different contexts, with different constituencies. I chose what I think of as several different windows through which to look at national security discourses... I believe that the continuities across ties are telling, and significant... The persuasiveness of my study derives from and must rest upon the very multiplicity of spaces within which I trace metaphoric gendered themes and their variations in the production of national security paradigms, policies, and practices.

In this view, methods developed in feminist IR scholarship gave way to the ethnographic turn in IR by allowing for intellectual space away from the positivist tradition and by exploring concrete ways to link everyday life inquiries to IR topics, processes and structures. These are significant parameters through which IR's engagement with, expectations and overall understanding of ethnography as methodology have been shaped and limited.

For scholars such as Wanda Vrasti (2008:281), the ways in which feminist IR and the proponents of the ethnographic turn have engaged with the methodology have been only "selective, instrumental and somewhat timid". The author argues that ethnography in IR is often reduced to a "data-collecting machine" that does not question the authenticity of what is gathered empirically; a genre of writing that seems accessible and highlights the subjectivity of the researcher; and a broad commitment to everyday life inquiries of the international with no other specific aim (Vrasti 2008:281). As she indicates, this limited usage of ethnography stems in part from what is required in the field: 
The regulatory mechanisms of disciplinary IR are such that extra-disciplinary efforts are granted a 'workers' visa' only if they conform to already-existing criteria for good research and unless they do anything to perturb the ontological imagination of the discipline (Vrasti 2008: 297).

In her view, IR's engagement with this methodology has been limited by the disciplinarity at play in the field, as ethnography became recognised only to the extent that it would accommodate IR's main goals.

Vrasti has been criticised for being a gatekeeper who idealises ethnography and ignores successful qualitative IR attempts that are broadly in line with the spirit of ethnography (see Aradau and Huysmans 2014; Lie 2013; Rantacore 2010; Neumann 2010). Vrasti sees ethnography as a methodology that critical IR scholars often invoke for its reputation, though they do so without properly conducting and engaging with it. As such, her critique is aimed at IR's limited engagement with the history of the methodology and the decades of debates in fields like social anthropology. Limited by her own preference for post-positivist and reflexive deployments of ethnography in social anthropology, she argues that it should not be equated solely with a pre-set combination of interviews and observations, but rather is something that requires deep reflexive practice during fieldwork. Moreover, empirical representations gained through this methodology should not automatically become a new holy grail for IR scholars. Her scepticism about the use of ethnography in IR is its framing as a methodology newly discovered by the discipline, and that its use in the field does not come with the necessary training (Lie 2013:219; Neumann 2010:1055).

Despite the reflexive instincts built into privileged critical IR scholarship, the ways in which ethnography is conducted seem lost on a generation whose hopes for emancipatory IR approaches are based on this methodology. For Marshall Beier (2005: 7), IR's disciplinarity is partly responsible for "students and scholars of International Relations [being] decidedly ill-prepared for the sort of ethnographic research and writing they are increasingly undertaking" (Beier 2005: 7). As Paul Kirby (2016:155) says, in a sort of confessional tone:

Fieldwork is an unjustly substantive term for what I did... I accumulate anecdotes, but nothing that feels like depth knowledge. That is, of course, a lesson in itself. 'The field' is a mirage of authenticity and true discovery, and the proofs we bring back more like fragments to be stitched into a story that will always be unstable.

Vrasti, referring to the process of translating fieldwork to written form Vrasti (2010:86), similarly highlights some of the unspoken precepts that make IR and ethnography difficult to reconcile based on the training its scholars receive: "It is in writing that the fantasy of valid truth is produced, by taking ourselves out of our projects, treating the world around us as evidence and subsuming social reality to explanatory methods and theories."

Some of this ill preparedness can also be explained by the complexity of conducting, in logistical and practical terms, an ethnography of the international. Working on foreign policy and diplomatic relations, Merje Kuus (2013) denotes problems with "studying up" the professional classes, of maintaining sustained access and building personal relationships with elite decision-makers and diplomats, especially in a context of high turnover and disinterest in academic knowledge production: "Clifford's casual phrase 
about hanging out appears jarring here because the power relations that favour the researcher in traditional ethnographic settings are often reversed in the study of foreign policy elites" (Kuus 2013:118).

This speaks not only of a logistical problem but also of the challenge that comes from combining ethnography with an investigation into state and inter-state realities. Many ethnographies of the international, whether in IR, social anthropology, sociology or other disciplines, have struggled with a focus on the state, as a "pre-empirical entity external to what may be grasped by ethnographical methods" (Lie 2013:207). However, there are lessons that can be gathered from how social anthropology has attempted to address this, including how to study states or political entities through their effects on everyday life, material practices and so forth. State-centrism can notably be avoided by limiting the focus on objects of second or third degree. For instance, David Mandelbaum (1973:180) suggests examining different dimensions of social life as main "devices for analysis", such as the cultural or the economic domain. They can then be conceived in juxtaposition with one another and give us a more complete understanding of how people order their lives, including the influence of political forms among other social structures at play. Similarly, both Edward Evans-Pritchard (1954), in his study of the Sanusi, and Mauss (2002), looking at the social function of exchanging gifts, examine transnational social realities without assuming the precedence of territorialised political entities in shaping people's habits, beliefs and lives. Evans-Pritchard (1954:69-70,103-104) explores how a mystical Muslim fraternity-the Sanusiya Order-with lodges across North Africa, integrated the Bedouin semi-nomadic social structure, and he does so to explain its unique developments, notably in reaction to Italian colonialism. Similarly, Mauss (2002) documents the interactions relating to the exchange of gifts between different societies for the purposes of trade, diplomacy and so forth, without assuming that this logic is inherently linked to an abstract raison d'État of the political communities involved.

Dealing with abstractions in ways that are not limited to bottom-up approaches can be further addressed by embracing more fully the hermeneutical circle and by developing a stronger interplay between theory and praxis, combining both inductive and deductive reasoning. As Geertz (1980) explains, his use of the hermeneutic circle may start from an inductive strategy of describing real-life events and encounters. However, this does not mean that ethnography is purely an inductive method, as it involves an ongoing engagement with theoretical tools both to accurately describe social facts and to offer some explanations. In Deep Play, Geertz (1973:412-453) shows how descriptions of specific events, interactions and rituals related to cockfighting in Bali are better comprehended when tools such as Jeremy Bentham's concept of "deep play", which is used to draw out the meanings of these activities, are deployed as part of understanding some specific features of Balinese society. However, such a concept is not applied blindly, as it remains in conversation with the empirical case. As such, Geertz adapts it and it becomes, alternatively, "deep fights", "deep matches" or "deep cockfighting"; hence, reflecting a particularly situated form of knowledge, anchored in theoretical connections to other scholarly topics and debates.

These lessons on how to avoid state-centrist and highly deductive methodologies can complement current IR disciplinary training. They can also help to avoid some of the pitfalls that come with deploying ethnography to understand the international. For Nina Glick Schiller (2003), this becomes a question of how abstractions are used within 
an ethnographical study and how they are represented in writing. She is notably wary of how abstract concepts can be deployed in ways that create the illusion of coherence and cohesion of the nation-state, which has direct consequences for representing inter-state and inter-societal relations. In her view, a strict conceptual framing prior to engaging with the empirical world is deeply problematic and antithetical to the ethnographic method. Responding to John Boreman's work and focus on such concepts to explain the state of the international order, she indicates that

concepts of political and public culture, when equated as in Borneman's article, with nation-states or bounded regions, lack the explanatory power to trace multiple transborder connections. These connections, including the pervasive force of US imperial power, are basic to the unequal and diverse power relationships that structure the globe and its 'separate' states (Glick Schiller 2003:297).

Glick Schiller (2003:298) is concerned with "analyses that equate society with the state", as they tend to sacrifice some of the inductive insights from fieldwork in describing and representing the world.

This point is relevant to critical IR scholarship that engages with the ethnographic method, which tends to navigate between the need for deductive ontological categories such as the state, and exposing subjugated knowledges based on how different collectives and individuals experience the international on their own terms. Critical IR scholars' attempts to move their inquiries beyond state-centrist and territorialised methodological precepts are met by a field that is disciplinarily and structurally developed on an abstraction of state sovereignty; the distinctive representation of anarchy between states and methodological preferences for quantitative and deductive approaches.

\section{Results and discussion}

\section{Tracing recent ethnographical accounts in IR}

James Clifford (1986), among others, has warned scholars that a commitment to ethnography often translates to an academic career lived on the margins, in many disciplines. In his view, ethnography is inherently interdisciplinary in nature, requires a style of writing that may not always be perceived as scholarly, and may come with doubts about the overall contribution of such work in view of an emancipatory research goal (Clifford 1986:7-13). This warning has not resonated much in IR. Whether through the recent scholarship associated with practice-focused research, autoethnography or multi-sited studies, IR's plural engagement with ethnography is mostly limited to a commitment to bringing representations of everyday life into the study of world politics. It also speaks of a political and ethical commitment to move away from the dominant state-centrist gaze in order to engage more directly with the international experiences of various groups on their own terms, in their structural relations with state and with global processes. This section documents how ethnography has been used recently in IR through three vignettes intended to give a sense of its specificity, while highlighting some parallels with questions present in other fields, especially social anthropology. 


\section{Practice-focused research}

In contrast to the vast majority of studies coming out of mainstream IR, critical scholarship in the field has identified, to various degrees, some value in utilising ethnography. In the various studies focusing on international practices, rather than theories or concepts, as a start to an academic inquiry, ethnography provides access to a mode of knowledge that was previously under-appreciated. From the scholarship associated with the practice turn to the scholarship associated with the aesthetic turn, IR's plural engagement with ethnography speaks to disciplinary disagreements over whether it is better understood as a method, among others, to collect new data or a unique methodology, with its own rules and standards.

The practice turn in IR scholarship, influenced by the work of Pierre Bourdieu and Bruno Latour, has steadily increased in importance since the early 2000s as a starting point for focusing on everyday actions and unquestioned common senses of the international. As such, it advocates for methodological plurality and co-existence in the study of world politics in order for mainstream theoretical approaches to be complemented by studies focused on specific material realities, perceptions and habits; hence, looking at "world politics through the lens of its manifold practices" (Adler and Pouliot 2011:3). The focus is on practices like diplomacy rather than on actors like states, as practices are understood as "competent performances" that are "socially meaningful patterns of action which, in being performed more or less competently, simultaneously embody, act out, and possibly reify background knowledge and discourse in and on the material world" (Adler and Pouliot 2011:6).

In this view, ethnography finds a role in and contribution to the study of IR, as it is seen as a methodology that can help us better understand the unfolding of IR practices, especially when performed by practitioners in the field. For instance, scholarship associated with the Paris School in critical security studies is part of this practice turn in IR, and has demonstrated how the globalisation of insecurity since 2001 can be better conceptualised by starting from the various changes in international practices. These include increased international professional collaborations in various fields relating to international security, such as surveillance, law enforcement and the military, and the ways in which related practitioners have developed new justifications, networks and resources to adapt to what is seen as a new security landscape. As Didier Bigo (2005:2) indicates:

since September 11th, 2001, the Western political world and the world of security 'experts' are turned to in a frenetic need to explain the relationships between domestic security and external defence, in a context of global insecurity that is neither discussed nor questioned (author's translation from French).

In the context of Western liberal democracies, Bigo makes it clear that a better comprehension of the perspectives and practices of these security professionals will help us understand new tendencies in how international security is conceived, planned, implemented and experienced. This approach is in line with other IR scholars associated with the practice turn and for whom greater use of ethnographic accounts, among other research methods, helps redefine IR's objects of study, realign theory and practice, and open up new avenues for a more inclusive and holistic research agenda (see Cornut 2014; Kuus 2013). 
Nonetheless, Adler and Pouliot (2011) limit their understanding of international practices to a criterion of competency, which is meant to help define the field of IR as Alexander Wendt (1992) did in the 1990s when he proposed a social constructivist framework for IR that does not question the existence of states. However, international practices are not limited to practitioners of the international, as many other actors get involved in matters and events with an international dimension, from theatre productions to social movements and global protests. IR scholars associated with the aesthetic turn have also deployed ethnography as a way to document marginalised perspectives and actions towards the international realm. By focusing on key everyday life practices and moments, the aim is to unpack sites of struggle, compliance and production of IR, no matter who the practitioner is. For instance, an edited volume directed by Edkins and Kear (2013) examines the intersection of international politics and performance to go beyond the "performance dynamics of politics" in order "to think them together as modes and practices of aesthetic politics". Whether it is through how theatrical performances bring visibility to silences in the practice of IR, how the perspective of rioters in 2011 in the United Kingdom inform debates over privacy laws, or how the staging of political speeches and protests work to reproduce international spaces, such a collection raises the question of who is competent enough to add their voice to a more complete understanding of IR practices. It also puts everyday moments, anecdotal events and banal groupings to the radar of those documenting and explaining the various rhythms of international politics.

Besides merely combining interviews and observations, the type of inquiry privileged by scholars of the aesthetic turn involves a vast engagement with ethnographic methods, both in terms of the type of writing used and how one engages fully with the "sensory aspects of perception" (Shapiro 2013:30). As Michael Shapiro (2013:31) notes, such studies put representations and perceptions of various actors front and centre, and are designed to document and analyse these worldviews through techniques that are under-utilised in IR, such as arts-based and event-specific participatory methods. For most IR scholars, this focus requires not only new types of methodological engagement, but also a re-definition of the "writing-inquiry relationships" and "writing as method", to something closer to the discussions of writing and representing results found in other disciplines (see Clifford 1986; Vrasti 2008). For example, Paul Dwyer documents and explains the role of Australia in the Bougainville civil war through a theatre project. Coined a photoplay, this documentary performance is a way to recoup and tell oral history material about this series of historical events (Dwyer, 2013:119). Where art meets international politics, Dwyer mixes in autoethnographical and autobiographical accounts of his life experiences in Bougainville, as he also revisits parts of his own heritage and the collective memory he can tap into as the basis for knowledge production and transmission about this international conflict. He explains his decision as follows:

My goal has been not so much, or not simply, to 'collect' the stories of Bougainvillean people and then to speak for them; rather, by digging up stories from my own family history and exploring just a few points of contact with the stories of Bougainvillean families, I have aimed to 'speak nearby' in an act of intimacy and solidarity (Dwyer 2013:114). 
When speaking of utilising his own perspective to relate to the ethnographical accounts at hand, Dwyer joins others associated with the aesthetic turn in deploying ethnography for academic purposes, far away from how it is considered by proponents of the practice turn.

As in other disciplines (see, for instance, in sociology: Ellis 2004; Smith 2005; Tavory and Timmermans 2014), one of the main debates arising from its distinct deployment is whether ethnography is just one among other methods for collecting new data, or a unique methodology with its own rules and standards. In IR, a conversation between two doctoral students, Rantacore (2010) and Vrasti (2010), sums up how the debate generally unfolds in the field. Opposing Vrasti's claim that there is a right way to conduct ethnography, Rantacore, 2010 argues that ethnography is only one "particular mode of access" among others that reinforces IR's goal "to assemble data, [and] to compose it in a way that is useful to our community of practice".

Vrasti (2010:85) responds to this critique by highlighting how integrating ethnography as merely a method into IR's knowledge production machine is to misunderstand what ethnography is and does:

Rancatore's preoccupation with research design seems to imply that, if only ethnography conformed to the explanatory ambitions of social science research, it would obtain 'parental approval' from IR... Ethnography cannot be included in the disciplinary toolbox because it rejects the onto-epistemological assumptions that make IR possible in the first place.

In her view, ethnography is not just a method, and, when properly applied as a methodology, it defies the abstractions on which IR as a field is built. It also includes "language competency, cultural sensibility and social etiquette" (Vrasti 2010:83), all elements of fieldwork that are usually under-valued in IR training (see also Agathangelou and Ling 2004).

For Aradau and Huysmans (2014:606), this confusion about what ethnography is in IR comes from the dominance of ontological and epistemological debates in its recent disciplinary history:

Understanding methods as connecting and assembling of ontology, epistemology, concept development, techniques of data gathering and worlds - rather than simply being the expression of ontological and epistemological choices - is an important step.

Besides being idealised in many ways in critical IR scholarship, ethnography is often chosen as a method for expressing a commitment to post-positivist research in the field, which does not give proper consideration of the methodology in the research process (Aradau and Huysmans 2014:597, 608-609).

In other academic disciplines, ethnography is conceived "as method and methodology" (Brewer 2000:28; Lewis and Russell 2011:398), as it involves both the rules and procedures to collect information and the framework through which this type of information is valued (Brewer 2000:7). In contrast to the Vrasti-Rancatore debate, we find accounts of doctoral students trained in this perspective who engage more directly with 
the importance of fieldwork itself (Lewis and Russell 2011:399). For instance, Teuku Zulfikar (2014) discusses not only experiences of conducting interviews and observations, but also how to gain and sustain access to the group, how to write one's personal narrative alongside thick descriptions and how struggles with ethical and reflexive questions unfolded. This is reflective of how well-established ethnographers have negotiated their methodological preferences. Clifford Geertz's (1973) description of anecdotal events and observations of cockfighting and betting in Bali is intertwined with his analysis of key Balinese societal features. In addition, he provides key methodological insights on how to effectively conduct this type of investigation of various cultures. As he states: "The culture of people is an ensemble of texts, themselves ensembles, which the anthropologist strains to read over the shoulders of those to whom they properly belong" (Geertz 1973: 452).

In addition to being the subject of IR debates over its method (ological) status, ethnography is perceived in many disciplines, such as social anthropology, as a way to access a particular type of knowledge. Whether conducted through first-hand experiences or through historiographical work (Geertz 1980; Mandelbaum 1973), ethnography refers to an array of methodological approaches with an attitude similar to "being there' sufficient to experience the mundane and sacred, the brash and nuanced aspects of socio-cultural life" (Lewis and Russell 2011:400). In this way, ethnography makes its own contribution to the advancement of knowledge, and social anthropologists themselves are the first ones to distinguish these contributions from other types of contributions; ethnographers "crawl on all fours with a magnifying glass, rather than circling the world in a helicopter looking at societies with a pair of binoculars" (Eriksen 2005:29). Such a perspective on the vast array of ethnographical approaches, along with the role of ethnography in relation to other methodologies and the valuing of fieldwork experience, seem to provide a justification for IR to move beyond theoretical questions on how to deploy it.

\section{Autoethnography}

In IR, autoethnography stresses in its own way how the personal is co-constitutive of the representation of the international realm for and by IR scholars, and also stresses the ethical implications of considering how one represents the world (Löwenheim 2010:1028-1032). As Neumann (2010:1053) explains: “Autoethnography is a methodological choice for researchers who place their philosophical ontological wager on themselves being an inseparable part of the world." Emphasising and celebrating their subjectivity, autoethnographers-which in IR are often conflated with autobiographers, narrators and storytellers-commit to an understanding of the social world, and its structures of oppression, through their own travels and experiences (Inayatullah and Dauphinee, 2016; Neumann 2010:1055). Discussions about autoethnography in IR have contributed to debates about the validity of findings gathered by IR researchers using ethnography and the role of scholars in representing world politics.

Needless to say, autoethnography in IR is widely perceived as radical and at odds with mainstream methodological preferences for objectivism, rationalism and positivism: "Research is all about a person's engagement with an issue. But most approaches to International Relations actively discourage involvement by the researcher" (Brigg and 
Bleiker 2010:779). For many critical IR scholars, the turn to autoethnography is a way to express frustration and disbelief with the preferred methodological choices of the discipline. As Roxanne L. Doty (2010:1047) expresses:

This interest is a symptom of a profound discontent on the part of some International Relations scholars with the dominant modes of research and writing and with the presumption that the writer must be absent from his/her own work in order to be legitimate.

Autoethnographers contend that "the self can become a more legitimate source of knowledge about International Relations" (Brigg and Bleiker 2010:780) than what is seen as valid knowledge in mainstream IR scholarship. More than a reaction to disciplinary preferences, autoethnography also deconstructs the role of academic expertise based on fieldwork, and highlights the implicit violence of academic representations of the world. Through increased awareness of their actions, autoethnographers shed light on connections between one's research and subjectivity in order to identify various possibilities for representing the inner workings of international power relations in new, more ethical ways (Dauphinee 2010:802-806; Doty 2010:1048-1049).

IR scholars use autoethnography to celebrate storytelling and accessible language, as distinct from a conventional "academic posture", to show how their background and experiences of the international have affected and are actively part of their scholarship (Inayatullah and Dauphinee 2016:2). It is important to note that many IR scholars have utilised autoethnography only once or twice in their writing, often as a way of connecting the dots between their professional objectives and personal lives. Oded Löwenheim (2010:1025) makes this objective clear: "to connect with as many readers as possible and make them, through their emotional response to my personal story, reflect upon their own experience as human beings and the constitution of their own subjectivity". For instance, Persaud (2016) explains his immigrant journey from the Caribbean in the 1970s and his integration into Canadian society: "The village man must learn to manage his eyes, to smile always, walk thusly, and learn to function like a self-contained moving part in a gigantic machine of production and consumption in an economy of fabricated, transient desires". Sharing lessons he has learned in how to act in this new country, Persaud demonstrates how this journey has given him a different perspective on researching racial, immigration and cultural issues in the field.

Similarly, Pin-Fat (2016) and Picq (2016) discuss their first encounters with what is considered the international realm in their personal lives, and how everyday life choices have influenced their political and academic commitments. Whereas Pin-Fat (2016) is sceptical of this exercise of recollection, noting that "the phenomenon of a self as 'sometimes here, sometimes not' raises a question for me about the 'solidity' - the ontological hardness of a self with which one may identify at certain moments", Picq (2016) establishes clear connections between her personal passion for flying and her academic interests in IR:

The other things that I learned in Brazil was to look up. Rio was not only a surfing spot, it also had beautiful flying conditions... My goal was to fly. Academia became the path of least resistance because it offered free time and fellowships [and] flying gave me unique insights into the international. 
Using autoethnography allows increased awareness of and reflexivity on the abstraction that defines the field-the international-to better grasp how it is shaped by the academics' own decisions and experiences, their evolving sense of what makes an international issue worth of studying and what shapes this understanding.

This deployment of ethnography is opposite to the uses of ethnography by many proponents of the practice turn and related understandings of what makes for valid studies. In IR, the role of the research in representing findings had been discussed before ethnography was thought of as a methodology associated with the field's critical scholarship. Coined as the "third debate" and opposing rationalist methodological preferences for post-positivist and reflexive perspectives, the epistemological difference between seeing the IR scholar either as an objective researcher collecting data in a disinterested manner or as a subjective presence involved in representing findings has led to distinctive types of privileged methodologies (see Keohane 1988; Navon 2001; Wendt 1998). Questions about the validity of the representations that IR academics create when they use ethnography have built on this literature but can also be seen in a different light when situated in relation to similar questions and debates in social anthropology.

This automatic association between ethnography and reflexive perspectives is less pronounced in other disciplines, especially in social anthropology, where autoethnographical accounts have integrated the discipline's knowledge production and representation in different ways. For instance, Mandelbaum's (1973:178) study of life history as an ethnographical methodology highlights the importance of "researchers' own life experiences" in selecting the approach, as it aims at uncovering a type of knowledge that could be considered true and real but that does not have specific scientific pretensions. The intent here is to discover social facts and realities by shedding light on the commonality of the human condition and the emotional structures at play. In blurring IR's disciplinary lines between objectivist and subjectivist research commitments, even Geertz (1973:453) utilises autoethnographical accounts as a way to connect to his object of study, to effectively frame the writing of his formal descriptions, and to commit more deeply to resolving the methodological struggle of "saying something of something' and saying it to somebody".

For Mary Louise Pratt (1986), the difference from IR is that there is a disciplinary need in social anthropology to strike a balance between offering impersonal descriptions of an object of study and revealing the role of the researcher's personal experiences in representations. Speaking of the 1982 controversy around Florinda Donner's account of the Yanomamo, she says: "What was at issue was not ethnographic accuracy, but a set of problematic links between ethnographic authority, personal experience, scientism, and originality of expression" (Pratt 1986:29). Donner's more reflexive stance in presenting her fieldwork was questioned not because of empirical inaccuracies but because of her choice to explicitly acknowledge her personal involvement in the representations made. For Pratt, this type of debate is part "disciplining" and part "un-disciplining", as it allows an academic community to navigate between "personal and scientific authority, a contradiction that has become especially acute since the advent of fieldwork as a methodological norm" (Pratt 1986:32). With the increasing interest in ethnography in IR, disciplinary debates may lead also to new perspectives on methodological norms, especially norms for fieldwork, and to a recognition of how different ethnographic findings from distinct epistemological standpoints may be productive, particularly when these standpoints are in conversation with one another. 


\section{Multi-sited studies}

As previously mentioned, feminist IR scholars like Carol Cohn (2006) have turned to Marcus' (1986) multi-sited ethnography as an alternative methodology for their inquiries, in belief "that the continuities across sites are telling, and significant" (Cohn 2006: 107). In the 1980s, ethnography was identified as a reputable and reliable methodology for critical IR scholarship interested in making linkages between everyday life and global processes. Even if Marcus' approach is contested within social anthropology and is far from a classical approach (see Falzon 2009; Hage 2005), it has been privileged in IR in the form of multi-sited studies with ethnographic sensibilities. The reason is that the emphasis on connections between different territorial sites and distinct perspectives of selected groups in their everyday lives allows scholars to justify their inquiries as part of IR's main contribution to knowledge, while opening up the field to new subjugated knowledges. Nonetheless, methodological questions arise in other fields on the ways in which a priori case selection can occur.

In IR, bottom-up approaches to the world are limited by a disciplinary need for a pre-empirical understanding of world politics and its main processes and structures. Even in critical scholarship, Kai Koddenbrock (2015:245) argues that in "the academic field tasked with studying world politics... systemic logics cannot be grasped by focusing exclusively on the minute details and their unstable assemblages". Although helpful to understand "the 'mess' that is social life", methodologies such as ethnography tend to limit IR scholarship in their necessity to "think big, to assert stability, totality and structure" (Koddenbrock 2015: 246). Privileging himself a Marxist understanding of world politics through a clear pre-empirical assertion of global capitalism, Koddenbrock joins other critical IR scholars for whom some limitations to ethnography can be found in the necessity to posit the structure(s) at play prior to investigating social life (see Muppidi 2013; Shani 2008; Withworth 1994).

It is in this disciplinary context that the logic behind multi-sited studies has been taken on, in different ways, by critical IR scholarship. As Marcus mentions Marcus (1995), multi-sited ethnography takes shape "around chains, paths, threads, conjunctions, or juxtapositions of locations in which the ethnographer establishes some form of literal, physical presence, with an explicit, posited logic of association or connection among sites". In contrast to traditional ethnographic methods, what the author proposes is an object of study that is most appropriate for IR scholars interested in new emancipatory ways to conduct research away from state-centrist methodological assumptions, at a time when the importance of globalisation emphasises the need for new ontological avenues (Marcus 1995:101-102). As with the disciplinary instincts of IR, this methodology requires one "to start with some prior view of a system and to provide an ethnographic account of it, by showing the forms of local life that the system encompasses", or "to construct the text around a strategic selected locale, treating the system as background" (Marcus 1986:171-72).

Such a strategy is notably popular in edited collections of critical IR scholarship, where ethnographical accounts of world politics can be combined with structural analyses. For instance, a key figure in IR's ethnographic turn, (Beier, 2005:10) explains the relevance of such accounts in an edited collection focused on the militarisation of childhood beyond the Global South. His explanation is as follows: 
of particular interest through the chapters that follow, then, are the multifarious ways that childhood is militarised beyond the global south through enactments of militarism that have drawn much less in the way of critical inquiry. Confronting such enactments and exploring their relatively more subtle and oft times surprising circulations is a principal aim of the volume, and one which brings into relief the under-interrogated and everyday ways in which children's lives are militarised in less scrutinised contexts and settings.

Beier's collection offers a way of bringing the messiness and complexity of everyday experiences back to the forefront of studies of international processes, while justifying itself structurally and disciplinarily to IR's goals.

Individual IR scholars working on emerging topics that deconstruct and complement state-centrist approaches to world politics also have committed to multi-sited studies. For instance, Heather Johnson (2014b:363-364) appropriated Marcus' approach to the study of migration regimes in Australia, Spain/Morocco and Tanzania, as this method focuses on "associations and connections between sites". By looking at sites where migration regimes reveal themselves, such as refugee camps, border zones and detention centres, she collects and presents peoples' narratives to highlight a common experience she characterises as a condition of irregular migration. Johnson's (2014a:16) choice of these "sites of intervention" allows for exploring "the interconnectedness of local sites at the global level," gives room for participants to express subtleties of daily life and for her to connect them through the conceptual lens of migration processes.

Similarly, Marianne Franklin (2004) offers ethnographical vignettes of the Internet communities and online practices of South Pacific Islanders starting in the second half of the 1990s in order to explore the intersections and interactions between online market forces, and Tongan and Samoan societies. As she notes:

It involves the movement of financial and in-kind remittances between countries and within dispersed family and social networks; conflicting sociocultural expectations for second and third generations growing up in the West, albeit often as disadvantaged groups therein; urbanised versions of 'ancient rivalries'; and political contestation or support of sociopolitical establishments 'back home' (Franklin 2004:7-8).

With a clear political commitment to documenting the practices of online community members in their daily lives, Franklin collects the stories of participants in these communities and makes linkages to transnational processes and global structures she sees at play, including questions of gender ordering, diasporic identity-formation, ethnic change and democratisation. In this view, the author not only pluralises IR's understanding of the international ramifications of new technologies in inter-state relations but also contributes to different interdisciplinary discussions about contemporary and deterritorialised Pacific Islander societies.

Some methodological questions remain in IR towards multi-sited studies, similar to how the deployment of ethnography to examine boundless, deterritorialised communities and related transnational processes have been discussed in social anthropology (see Candea 2009; Hage 2005). To what extent is Johnson (2014a, b) examination of irregular migration really found in the selected sites of intervention, if this ontological category and innovative 
concept is created prior to fieldwork? How are these sites of intervention chosen, if not due to an a priori understanding of world politics? It is important to note that Marcus (1986, 1995) struggled with such questions during the elaboration of his multi-sited strategy. One of his initial problems was that, methodologically, "the narrative complexity is considerable" and it becomes difficult, in his view, to select the right sites of interventions and voices, without falling into anecdotal knowledge (Marcus 1986:172).

Marcus' approach is developed in conversation with a rich body of literature dealing with such methodological questions-a disciplinary history and cannon with which IR scholars are less familiar and engaged. As previously mentioned, studies by Geertz (1980) and Mandelbaum (1973) have shown how to deploy historiography and life history as ethnographical methodologies that bring the importance of temporality and moments back into any multi-sited analysis, often bridging various physical locations and political communities in order to highlight key features of a society or place in time. More to the point, ethnographical work, such as Mauss (2002) on gifting, shows how this system of interactions commonly exists in various North American and Asian societies as an ordering factor of domestic and inter-societal relations. Mauss's work also presents their cultural, historical, institutional and geographical differences. Through an analysis of these systems of reciprocal obligations, Mauss offers both clear comparative insights and an overall explanation of the social function of this interaction in and between various societies.

In contrast to Marcus' multi-sited strategy, social anthropologists, such as Pederson and Holbraad (2013), as well as Abélès (2011), have recently offered another strategy, closer to such classical influence. For instance, Pederson and Holbraad (2013:2) conceive of comparative ethnography as a more productive approach, allowing for a simple but effective overall finding: "(in) security can be simultaneously enacted within and across multiple temporal logics, whose complex imbrications may be studied ethnographically and compared with other times of security". In the authors' view, such an approach is more revealing than the methods normally privileged in IR, if for no reason other than that the researcher is not conceptually characterising experiences as insecurities, at least not in a way that goes beyond what participants express (Pederson and Holbraad 2013:8-11).

\section{Conclusions}

By providing recent accounts of the interpretations and uses of ethnography in IR, this paper unpacks how the methodology is understood within this academic discipline and the specific challenges that come with conducting ethnographies of the international, from the lack of training for IR scholars to disciplinary and logistical obstacles. Engagements with ethnography have been visible mostly since the field's ethnographic turn in the 1990s, and are found most notably in work associated with the practice turn, the aesthetic turn, autoethnography and multi-sited studies. The appeal of ethnography for critical IR scholarship is that it helps the researcher move beyond discursive analyses, to put mainstream studies in perspective by focusing on everyday sites of the international, subjugated knowledges and under-explored linkages between the local and the global. In contrast to other academic disciplines, ethnography is mostly deployed from a post-positivist and reflexive standpoint, as it is seen as a methodological counterweight to mainstream approaches privileging rationalist and quantitative methodologies. 
As pointed out by others, it is deeply problematic to understand ethnography in IR only by reference to the field's ethnographic turn, in particular because the latter focuses on analyses that either study international elites and professionals, or appropriate the experiences of marginalised populations caught up in cross-border processes (see Aradau and Huysmans 2014; Vrasti 2008). Taking the ethnos out of ethnography may fit IR's disciplinary mindset, as it actively erases decades of debates about interpreting and using ethnography, as found in other academic disciplines, such as social anthropology and sociology. The classical anthropological literature reveals a lot about colonialism and imperialism as global structures and their everyday consequences. However, it is left out of the IR corpus, as is the vast majority of non-Western autoethnographical and autobiographical accounts of specific international moments of world history (Anievas et al. 2015; Evans-Pritchard 1954; Geertz 1980; Grovogui 2006; Mandelbaum 1973).

For some IR scholars who are committed to post-colonialism, decolonial thinking and critical ethnic and racial studies, this exclusion of historical ethnographies and social anthropology's debates on the colonial uses of the methodology is linked to the latent racist tendencies and white supremacist mentality that remains unquestioned in the field of IR. This disciplinary logic is partly responsible for the non-recognition of key academic contributions in its canon, such as W.E.B. du Bois' work on the global colour line as the main international structure of the twentieth century. It also implies active forgetting of the racialised roots of the discipline and some efforts to sanitise and white-wash its history, including forgetting how a key academic journal in IR, namely, Foreign Affairs, was formerly entitled the Journal of Race Development. And it impacts teaching in IR, which marginalises how racism is deployed as a foreign policy tool, as it was with Arthur de Gobineau coining the myth of Aryan supremacy as a foreign policy pillar of the Third Reich. Even if IR as an academic field contributes to an overall understanding and explanation of inter-state relations and international ordering principles, the erasure of racialised dynamics and realities is deeply problematic. This is especially true of the erasure of academic material, including classical ethnographies, that helps students and scholars alike learn about and reflect on their role as structuring forces. This erasure not only limits the ability of IR scholars to engage fully with the reality they wish to understand and explain, but it also arbitrarily reduces what counts as relevant knowledge in the field to the detriment of already available sources, including Indigenous and non-Western knowledges (Anievas et al. 2015; Beier 2005; Grovogui 2006; Le Melle 2009; Vitalis 2005).

If ethnographies are meant to convey how specific populations see the world and how their reality is uniquely integrated into the world, it is not surprising that many of them have been excluded from the study of IR, a field based on theories and debates that erase questions of race and racism. Disciplinarily, it makes sense for IR to limit any serious engagement with studies based on ethnography-and related debates about inductive research, participant-led approaches and the problems of representation-if only to limit methodologically the types of voices recognised as legitimate, and epistemologically to devalue non-Western knowledges. Whereas ethnographies speak directly to realities, topics and interactions that are inherently international-especially as they are conducted in the social anthropology tradition, among other fields-IR's disciplinary blinders still limit sustained interdisciplinary conversations that could benefit from a richer and more fruitful deployment of ethnography to study inter-state and inter-societal relations. 


\section{Abbreviations}

IR: International relations; OMC: Organisation mondiale du Commerce (World Trade Organisation)

\section{Acknowledgements}

Earlier versions of this paper were presented to a workshop held at the Chinese Academic of Social Sciences in August 2017, a graduate seminar at the University of Ottawa in December 2017 and a public event at Dalhousie University in February 2018. Thanks are due to all participants having provided comments and suggestions, and especially Hélène Pellerin and Ajay Parasram. The views expressed here are my own and should not be attributed to anyone else.

\section{Author's contributions}

The author conducted all stages of this research. The author read and approved the final manuscript.

\section{Author's information}

Jean Michel Montsion is an Associate Professor at the Department of Multidisciplinary Studies at York University in Toronto, Canada.

\section{Competing interests}

The author declares that he has no competing interests.

\section{Publisher's Note}

Springer Nature remains neutral with regard to jurisdictional claims in published maps and institutional affiliations.

Received: 27 December 2017 Accepted: 4 July 2018

Published online: 19 July 2018

\section{References}

Abélès, Marc, ed. 2011. Des anthropologues à l'OMC: scènes de la gouvernance mondiale. Paris: CNRS Editions.

Adler, Emanuel, and Vincent Pouliot. 2011. International practices: introduction and framework. In International Practices, ed. by, ed. E. Adler and V. Pouliot, 3-35. Cambridge: Cambridge University Press.

Agathangelou, Anna, and Lily Ling. 2004. The house of IR: from family power politics to the poisies of worldism. International Studies Review 6 (1): 21-49.

Anievas, Alexander, Nivi Manchanda, and Robbie Shilliam, eds. 2015. Race and racism in international relations: confronting the global colour line. New York: Routledge.

Aradau, Claudia, and Jef Huysmans. 2014. Critical methods in international relations: The politics of techniques, devices and acts. European Journal of International Relations 20 (3): 596-619.

Ashley, Richard. 1988. Untying the sovereign state: a double reading of the anarchy problematique. Millennium 17 (2): 227-262.

Ashworth, Lucian. 2002. Did the realist-idealist great debate really happen? A revisionist history of international relations. International Relations 16 (1): 33-51.

Beier, Marshall. 2005. International relations in uncommon places: indigeneity, cosmology, and the limits of international theory. New York: Palgrave Macmillan.

Bigo, Didier. 2005. La mondialisation de l' (in) sécurité? Réflexions sur le champ des professionnels de la gestion des inquiétudes et analytique de la transnationalisation du processus d'insécurisation. Cultures \& Conflits 58: 1-35.

Brewer, John D. 2000. Ethnography. Philadelphia: Open University Press.

Brigg, Morgan, and Roland Bleiker. 2010. Autoethnographic international relations: Exploring the self as a source of knowledge. Review of International Studies 36 (4): 779-798.

Candea, Matei. 2009. Arbitrary locations: in defence of bounded field-site. In Multi-sited ethnography: theory, praxis and locality in contemporary research, ed. M.A. Falzon, 25-46. Aldershot: Ashgate.

Clifford, James. 1986. Introduction: Partial truths. In Writing culture: the poetics and politics of ethnography, ed. J. Clifford and G.E. Marcus, 1-26. Berkeley: University of California Press.

Cohn, Carol. 2006. Motives and methods: using multi-sited ethnography to study national security discourses. In Feminist methodologies for international relations, ed. B. Ackerly, M. Stern, and J. True, 91-107. Cambridge: Cambridge University Press.

Comaroff, Jean, and John Comaroff. 1992. Ethnography and the historical imagination. Boulder CO: Westview Press.

Comaroff, Jean, and John Comaroff. 2003. Ethnography on an awkward scale: postcolonial anthropology and the violence of abstraction. Ethnography 4 (2): 147-179.

Cornut, Jérémie. 2014. La fin des relations triangulaires Ottawa-Québec-Paris? Harper, la 'diplomatie robuste' et les relations France-Canada. Canadian Foreign Policy Journal 20 (1): 86-95.

Cox, Robert W., and Timothy Sinclair. 1996. Approaches to world order. Cambridge: Cambridge University Press.

Dauphinee, Elizabeth. 2010. The ethics of autoethnography. Review of International Studies 36 (4): 799-818.

Doty, Roxanne L. 2010. Autoethnography-making human connections. Review of International Studies 36 (4): $1047-1050$

Dwyer, Paul. 2013. Theatre as post-operative follow-up: the Bougainville photoplay project. In International politics and performance: critical aesthetics and creative politics, ed. J. Edkins and A. Kear, 113-129. London: Routledge.

Edkins, Jenny, and Adrian Kear. 2013. Introduction. In International politics and performance: critical aesthetics and creative politics, ed. J. Edkins and A. Kear, 1-15. London: Routledge.

Ellis, Carolyn. 2004. The ethnographic l: a methodological novel about autoethnography. New York: AltaMira Press.

Eriksen, Thomas H. 2005. Engaging anthropology: the case for a public presence. New York: Berg.

Eriksen, Thomas H., and Iver B. Neumann. 1993. International relations as a cultural system: an agenda for research. Cooperation and Conflict 28 (3): 233-264. 
Evans-Pritchard, Edward. 1954. The Sanusi of Cyrenaica. London: Oxford University Press.

Falzon, Mark-Anthony, ed. 2009. Multi-sited ethnography: theory, praxis and locality in contemporary research. Aldershot: Ashgate. Franklin, Marianne. 2004. Postcolonial politics, the internet and everyday life: Pacific traversals online. New York: Routledge. Geertz, Clifford. 1973. The interpretation of cultures: selected essays. New York: Basic Books.

Geertz, Clifford. 1980. Negara: the theatre state in nineteenth-century Bali. Princeton: Princeton University Press.

Glick-Schiller, Nina. 2003. Same old same old? Resurrecting political culture or conducting ethnographies of human possibilities? American Ethnologist 30 (4): 497-499.

Grovogui, Siba N. 2006. Beyond eurocentrism and anarchy: memories of international order and institutions. Basingstoke: Palgrave Macmillan.

Hage, Ghassan. 2005. A not so multi-sited ethnography of a not so imagined community. Anthropological Theory 5 (4): 463-475.

Hoffman, Mark. 1993. Critical theory and the inter-paradigm debate. Millennium 16 (2): 231-250.

Hollis, Martin, and Steve Smith. 1990. Explaining and understanding international relations. Oxford: Clarendon Press.

Hua, Cai. 2008. L'homme pensé par l'homme: Du statut scientifique des sciences sociales. Paris: Presses universitaires de France. Inayatullah, Naeem, and Elizabeth Dauphinee. 2016. Permitted urgency: a prologue. In Narrative global politics: theory, history and the personal in international relations, ed. N. Inayatullah and E. Dauphinee, 1-5. New York: Routledge. Johnson, Heather L. 2014a. Borders, asylum and global non-citizenship. Cambridge: Cambridge University Press. Johnson, Heather L. 2014b. Ethnographic translations: bringing together multi-sited studies. Critical Studies Security 2 (3): $362-365$.

Keohane, Robert. 1988. International institutions: two approaches. International Studies Quarterly 32 (4): 379-396.

Kirby, Paul. 2016. Auto/bio/graph. In Narrative global politics: theory, history and the personal in international relations, ed. N. Inayatullah and E. Dauphinee, 153-158. New York: Routledge.

Koddenbrock, Kai J. 2015. Strategies of critique in international relations: from Foucault and Latour towards Marx European Journal of International Relations 21 (2): 243-266.

Kuus, Merje. 2013. Foreign policy and ethnography: a sceptical intervention. Geopolitics 18 (1): 115-131.

Le Melle, Tilden. 2009. Race in international relations. International Studies Perspectives 10 (1): 77-83.

Lewis, S.J., and A.J. Russell. 2011. Being embedded: a way forward for ethnographic research. Ethnography 12 (3): 398-416.

Lie, Jon. 2013. Challenging anthropology: anthropological reflections on the ethnographic turn in international relations. Millennium 41 (2): 201-220.

Löwenheim, Oded. 2010. The 'I' in IR: an autoethnographical account. Review of International Studies 36 (4): 1023-1045. Mandelbaum, David. 1973. The study of life history: Gandhi. Current Anthropology 14 (3): 177-206.

Marcus, George E. 1986. Contemporary problems of ethnography in the modern world system. In Writing culture: the poetics and politics of ethnography, ed. J. Clifford and G.E. Marcus, 165-193. Berkeley: University of California Press.

Marcus, George E. 1995. Ethnography in/of the world system: the emergence of multi-sited ethnography. Annual Review of Anthropology 24 (1): 95-118.

Mauss, Marcel. 2002. The gift: the form and reason for exchange in archaic societies. New York: Routledge.

Muppidi, Himadeep. 2013. On the politics of exile. Security Dialogue 44 (4): 299-313.

Navon, Emmanuel. 2001. The 'third debate' revisited. Review of International Studies 27 (4): 611-625.

Neumann, Iver B. 2010. Autobiography, ontology, autoethnology. Review of International Studies 36 (4): 1051-1055.

Pederson, Morten Axel, and Martin Holbraad. 2013. Introduction: times of security. In Times of security: ethnographies of fear, protest and the future, ed. M. Holbraad and M.A. Pederson, 1-27. New York: Routledge.

Persaud, Randolph. 2016. The reluctant immigrant and modernity. In Narrative global politics: theory, history and the personal in international relations, ed. N. Inayatullah and E. Dauphinee, 5-24. New York: Routledge.

Picq, Manuela. 2016. Simultaneous translation: finding my core in the periphery. In Narrative global politics: theory, history and the personal in international relations, ed. N. Inayatullah and E. Dauphinee, 35-51. New York: Routledge.

Pin-Fat, Véronique. 2016. Dissolutions of the self. In Narrative global politics: theory, history and the personal in international relations, ed. N. Inayatullah and E. Dauphinee, 25-34. New York: Routledge.

Pratt, Mary Louise. 1986. Fieldwork in common places. In Writing culture: the poetics and politics of ethnography, ed. J. Clifford and G.E. Marcus, 27-50. Berkeley: University of California Press.

Rantacore, Jason. 2010. It is strange: a reply to Vrasti. Millennium 39 (1): 65-77.

Ree, Gerard. 2014. Saving the discipline: plurality, social capital, and the sociology of IR theorizing. International Political Sociology 8 (2): 218-233

Schmidt, Brian. 1998. The political discourse of anarchy: a disciplinary history of international relations. Albany NY: State University of New York Press.

Shani, Giorgio. 2008. Towards a post-Western IR: The Umma, Khalsa Panth and critical international relations theory. International Studies Review 10 (4): 722-734.

Shapiro, Michael. 2013. Studies in trans-disciplinary method: after the aesthetic turn. New York: Routledge.

Small, Mario Luis. 2009. How many cases do I need: on science and the logic of case selection in field-based research. Ethnography 10 (1): 5-38.

Smith, Dorothy. 2005. Institutional ethnography: a sociology for people. New York: AltaMira Press.

Smith, Steve. 2000. The discipline of international relations: still an American social science? British Journal of Politics and International Relations 2 (3): 374-402.

Smith, Steve. 2004. Singing our world into existence: international relations theory and September 11. International Studies Quarterly 48 (3): 499-515.

Tavory, Iddo, and Stefan Timmermans. 2014. Abductive analysis: theorizing qualitative research. Chicago: University of Chicago Press.

Tickner, J. Ann. 2006. Feminism meets international relations: some methodological issues. In Feminist methodologies for international relations, ed. B. Ackerly, M. Stern, and J. True, 19-41. Cambridge: Cambridge University Press.

Vitalis, Robert. 2005. Birth of a discipline. In Imperialism and internationalism in the discipline of international relations, ed. D. Long and B. Schmidt, 159-181. Albany NY: State University of New York Press.

Vrasti, Wanda. 2008. The strange case of ethnography and international relations. Millennium 37 (2): 279-301. 
Vrasti, Wanda. 2010. Dr Strangelove, or how I learned to stop worrying about methodology and love writing. Millennium 39 (1): 79-88

Waever, Ole. 1998. The sociology of a not so international discipline: American and European developments in international relations. International Organization 52 (4): 687-727.

Walker, Rob. 2006. The double outside of the modern international. Ephemera: theory and politics in organization 6 (1): 56-69. Wendt, Alexander. 1992. Anarchy is what states make of it: the social construction of power politics. International Organization 46 (2): 391-425.

Wendt, Alexander. 1998. On constitution and causation in international relations. Review of International Studies 24 (5): 101-118.

Withworth, Sandra. 1994. Feminism and international relations: towards a political economy of gender in inter-state and non-governmental institutions. New York: St. Martin's Press.

Zalewski, Marysia. 2006. Distracted reflections on the production, narration, and refusal of feminist knowledge in international relations. In Feminist methodologies for international relations, ed. B. Ackerly, M. Stern, and J. True, 42-61. Cambridge: Cambridge University Press.

Zulfikar, Teuku. 2014. Researching my own backyard: inquiries into an ethnographic study. Ethnography 9 (3): 373-386.

Submit your manuscript to a SpringerOpen ${ }^{\circ}$ journal and benefit from:

- Convenient online submission

- Rigorous peer review

Open access: articles freely available online

High visibility within the field

- Retaining the copyright to your article

Submit your next manuscript at $\boldsymbol{\sim}$ springeropen.com 